Thonerde

Kieselsäure

Manganoxydul

Chlorcaesium

Chlorrubidium

Phosphorsäure

Krystallwasser und Verlust

Summa der Bestandtheile

$$
\begin{gathered}
\text { Transp.: } 31,3088 \mathrm{~g} . \\
0,0556 ", \\
0,2420 " \\
0,0013 " \\
\text { Spuren } \\
\text { Spuren } \\
\text { Spuren } \\
0,2410, \\
\hline 31,8487 \mathrm{~g} .
\end{gathered}
$$

Das Birresborner Mineralwasser ist somit eines der lithiumreichsten bekannten Heilwässer.

\title{
Mittheilungen.
}

Von Dr. F. A. Hartseu in Cannes in Südfrankreich.

Ueber Chrysophyll.

Das Vorkommen des von mir als Chrysophyll bezeichneten Stoffes, habe ich schon früher im chemischen Centralblatte*) erwähnt und war seitdem bestrebt, eine billigere Bereitungsweise zu finden.

Nan kann in der That zum Ausziehen und Krystallisiren dess. an Stelle des Aethers starken Weingeis t benutzen. ${ }^{* *}$ ) Es genügt, die frischen Blätter mit starkem Weingeist auszuziehen, die Tinctur abzupressen und bei einer $k$ ühlon Temperatur freiwillig verdunsten zu lassen. Man erhält dann einen Bodensatz von Fett und Chlorophyll, in welchem die prachtvollen, goldglänzenden Kryställchen des Chrysophylls eingebettet sind. Ist das Verdunsten etwas rorgeschritten, so sieht man die glänzenden Kryställchen in der Flüssigkeit schweben und wenn man auf dieselbe bläst, blitzartig sich hin und herbewegen.

*) S. Jahrg. 1873.

**) Ich erhielt das Chrysophyll als Nobenproduct der Chlorophyllbereitung aus Mercurialls perennis u. annua, Ulmus campestris, Aesculus Hypocastanum, Potamogetonect. 
Das Chrysophyll wird dann dadurch isolirt, dass man den Bodensatz rasch mit etwas Petroleurnäther schüttelt. Dieser löst das Chlorophyll und viel Fett, die Kryställchen des Chrysophylls bleiben mit etwas Fett und einem grauen Stoffe zurück, der dem Chlorophyll gleich durch Salzsäure smaragdgrün gefärbt wird. Aus diesem Gemenge kann man das Chrysophyll durch etwas Weingeist ausziehen, und erhält man bei freiwilligem Verdunsten und öfterer Wiederholung immer reineres Chrysophyll.

Durch concentrirte Schwefelsäure wird das Chrysophyll schön blau gefürbt. Vielleicht ist das Chrysophyll identisch mit dem Xantophyll von Fremy, jedenfalls aber kein Bestandtheil des Chlorophylls, sondern diesem einfach beigemischt. Das reine Chlorophyll ist grün. Ebenso möchte ich nochmals warnen, das Chlorophyll, nach dem Spectroscope aus unreinen Pflanzenauszügren bereitet, als Grundlage für die Zusammensetzung zu wählen. Hier in Cannes bereitete ich Chlorophyll aus Mercurialis im Januar.

\section{Ueber Kindermehl.}

\section{Von.Apotheker Dr. H. Müller.}

Unter dem Namen „Kindermehl “ kommen in den letzten Jahren Präparate in den Handel, die zur Ernährung von Säuglingen bestimmt sind und die eine solche Verbreitung und Wichtigkeit erlangt haben, dass Besprechungen derselben in unserem Archiv nicht nur berechtigt, sondern sogar geboten erscheinen, um Collegen, die sich weniger mit der Natur dieser Nahrungsmittel beschäftigt haben, über dieselben zu orientiren.

Zuerst war es bekanntlich Liebig, der cine rationelle Ernährung der Säuglinge für wichtig genug hielt, um dieselbe zum Gegenstand seiner Untersuchungen und Versuche zu machen, deren Ergebniss die Liebig'sche Suppe*) war. Die-

*) Annal. d. Chemie und Pharmac. 133, 374; 138, 97. Archiv der Pharm. (1865) 122, 241. 